\title{
Cultura, política e cotidiano: pilares de sustentação de um cinema periférico
}

\section{Gustavo Souza}

\section{Resumo}

A partir do cinema realizado em periferias urbanas brasileiras, este trabalho discute a composição e as funções de três importantes pilares que o sustentam: cultura, política e cotidiano. A perspectiva aqui adotada é que cultura, política e cotidiano se entrelaçam de forma contígua e se articulam na promoção do debate sobre o potencial dos produtos culturais em meio, também, às novas configurações da esfera política, que recorre ao cotidiano como uma estratégia para rever ordenamentos de imagens, enunciados e pontos de vista.

\section{Palavras-chave}

Cultura. Política. Cotidiano. Cinema de periferia.

\section{Gustavo Souza | gustav003@uol.com.br}

Doutorando em Ciências da Comunicação pela Escola de Comunicações e Artes da Universidade de São Paulo - ECA/USP.

\section{Introdução}

A produção cinematográfica brasileira que emergiu a partir da década de 90 foi fortemente marcada por novos itinerários para o documentário. Viu-se 0 crescimento de sua produção e sua posterior exibição, não somente em festivais ou mostras específicas, mas também em salas do circuito comercial, conferindo-lhe uma visibilidade há tempos não vista. Enquanto o documentário ganhava expansão perante 0 público, a crítica e os profissionais, moradores de subúrbios, morros e periferias começavam a experimentar uma outra forma de contar histórias: a partir de filmes realizados em oficinas de cinema e audiovisual espalhadas por diversas cidades brasileiras. Hoje, a necessidade de ter a clareza sobre o potencial de uma imagem e saber utilizá-lo é imprescindível, fazendo com que 0 periférico passe agora de personagem - que por décadas causou (e ainda causa, de certo modo) um intenso fascínio entre documentaristas - a realizador, a contador de sua própria história.

Assistir aos filmes dessa produção, em sua maioria documentários, conduz à necessidade 
de se apreender suas matrizes, isto é, perceber aspectos que a compõem, mas que muitas vezes são postos de lado diante da necessidade (ou preferência metodológica) de se deter diretamente nos produtos finais, ou seja, os filmes. Não quero com isso desmerecer a análise fílmica, pois foi exatamente 0 contato com um conjunto de documentários, de diversas oficinas, de várias partes do país que me conduziu à reflexão aqui proposta. Faço esta ressalva porque o texto que segue é resultado de uma visão panorâmica para este tipo de cinema. Visão esta que desvia o foco das análises mais localizadas para tentar assimilar tal cinematografia de maneira global. Com base nessa orientação, quero neste artigo sinalizar que cultura, política e cotidiano, como pilares que sustentam 0 cinema de periferia, atravessam mutuamente este tipo de produção - aspecto que merece ser debatido mais de perto. Atentar para esse triângulo não significa desmerecer outros pilares também importantes para a apreensão do cinema periférico. Fatores relacionados à tecnologia e à economia, por exemplo, também são importantes e serão discutidos, em menor proporção, nas páginas seguintes. Esta observação é necessária para que se evite 0 fechamento da reflexão em determinados aspectos, colocando-os como primordiais e únicos, desprezando as potencialidades de outros campos.

A perspectiva aqui adotada é de que cultura, política e cotidiano se entrelaçam de forma contígua para construir imagens e discursos políticos. Não se trata de privilegiar nenhum dos ângulos do triângulo assim definido, mas de mostrar a peculiaridade da relação que cada um deles estabelece com o cinema realizado nas periferias brasileiras. Cultura, política e cotidiano são planos irredutíveis, mas que podem ser investigados segundo uma mesma estratégia: às instâncias da instauração cultural corresponderão, mutuamente, às instâncias da política, e estas, por sua vez, às do cotidiano.

Dito isso, o debate tratará inicialmente da questão da cultura, ao recorrer a autores de diferentes tradições teóricas - Sociologia, Estudos Culturais e Teoria Pós-Colonial -, para, na sequência, perceber as articulações dos artefatos culturais (especialmente 0 cinema, na sua modalidade documentário) com processos que esgarçam a noção de política na construção de imagens e enunciados políticos que vão buscar no cotidiano as gradações necessárias para tais processos de constituição. Mesmo em searas acadêmicas distintas, e às vezes travando posicionamentos discordantes, os autores aqui escolhidos atravessam as fronteiras das áreas do saber e estabelecem uma teia em que prevalece o pensamento sobre as funções e os usos da cultura, da política e do cotidiano no cenário contemporâneo, e que aqui será de grande valia para 0 debate que segue.

\section{Cultura: usos e efeitos}

Os estudos que já se dedicaram ao tema cultura não são recentes. Eles estão localizados em 
inúmeras disciplinas e constituem um extenso arsenal bibliográfico. Não me interessa aqui traçar uma espécie de revisão bibliográfica, que revisitaria o tema em seus diferentes momentos, campos do saber e resultados. Mas perceber, a partir da perspectiva apresentada pelo corpus deste trabalho, como as reflexões empreendidas pelos autores selecionados contribuem para 0 debate. Dessa forma, as definições de cultura propostas por Raymond Williams tornamse um importante ponto de partida. Em sua classificação, Williams (2007) definiu cultura como um modo de vida compartilhado, como um desenvolvimento intelectual e estético particular e como as produções da atividade intelectual, especificamente a artística - literatura, pintura, teatro, música, dança, cinema. Tal postulado surgiu num momento em que predominava a circulação dos produtos culturais nos meios de comunicação de massa, bem como a efervescência da cultura popular, especialmente no contexto inglês. Logo, corroborar uma perspectiva que estabelecia níveis hierárquicos para a cultura, bem como enxergá-la unicamente pelo viés da antropologia, solapava toda e qualquer possibilidade de situar a cultura num horizonte dialógico. Isso fez 0 autor destacar de que maneira o mesmo objeto pode receber diferentes tratamentos em função da disciplina que 0 acolhe: "na arqueologia e na antropologia cultural, a referência à cultura ou a uma cultura aponta para primordialmente a produção material, enquanto na história e nos estudos culturais a referência indica fundamentalmente os sistemas de significação ou simbólicos".

(WILLIAMS, 2007, p. 122, grifos do autor).

Com base em tais definições, a cultura, em sua constituição e ação, transita entre as esferas do individual e do coletivo. Na primeira definição cultura como um modo de vida -, predomina um expoente que estabelece as diretrizes culturais para uma comunidade, para uma nação ou uma coletividade. A segunda concepção preza pelo aprimoramento das possibilidades intelectuais e estéticas do indivíduo. E para que se diga o quão "culto" pode ser alguém, é necessário considerar a produção, a circulação e 0 acesso a ideias e materiais teóricos ou artísticos, por exemplo, num determinado contexto social e histórico. Isso nos leva à terceira forma de cultura - a produção artística -, que pode surgir como uma iniciativa individual, mas que visa, em sua maioria, uma coletividade. Portanto, as definições de cultura propostas por Williams não são estanques, e sim conectadas entre si. A que me interessa mais de perto é a terceira, porque é nela em que se situa o cinema. Logo um detalhamento de sua composição se faz necessário.

Se a produção artística sofre as consequiências diretas do seu tempo histórico e social, esse tempo é atravessado hoje por uma série de fatores que se relacionam entre si de forma complexa, intensificados pela globalização. Por essa via, não se pode perder de vista que os processos culturais em tempos globalizados são 
o resultado de uma articulação entre diversos "panoramas" (APPADURAI, 1994), como os fluxos migratórios, a tecnologia, a economia e as finanças, bem como as mídias e ideologias que nelas circulam. Embora a discussão sobre as "disjunções e diferenças na economia cultural global" selecione para o debate esses cinco aspectos, a questão não se finda em identificá-los e esclarecer como eles operam individualmente, mas compreender suas influências mútuas.

Num momento em que pessoas, dinheiro, tecnologia, imagens e ideias podem se deslocar constantemente num itinerário pouco definido, rever o papel que a cultura exerce neste horizonte torna-se uma tarefa particularmente importante, pois a questão do território e da etnia deixam de ser o epicentro do debate para se tornarem pontos de partida. Este diagrama exige uma reelaboração da noção de cultura, em que é preciso pensá-la não mais como um sistema de significados ou uma propriedade que cada grupo ou indivíduo carrega consigo, mas como um recurso que conduz à descoberta e à invenção, permitindo pensar a diferença. Daí, a importância de se pensar no cultural, em vez da cultura, esclarece Appadurai: "Se cultura como substantivo parece suscitar a associação com uma qualquer substância de um modo que esconde mais do que revela, cultural, 0 adjetivo, transporta-nos para o reino de diferenças, contrastes e comparações bem mais útil" (2005, p. 26, grifos do autor). Esta perspectiva é importante porque evita a fetichização da cultura ou de qualquer outro "panorama". Num primeiro momento, pode-se reconhecer que as coisas partam inicialmente de um desses pólos, mas restringir 0 debate a esta constatação e "comemorá-la" como uma chegada ao topo mais alto do pódio das discussões acadêmicas pouco contribui para 0 debate. Uma compreensão mais aprofundada dos desígnios da cultura só será possível num momento em que se abandonam perspectivas normativas e redutoras para perceber que articulações são possíveis apreender a partir daí, e como elas transformam os contextos históricos ou o nosso cotidiano.

Como se vê, a globalização desenha novos cenários para a cultura. A diversidade de abordagens sobre a relação entre cultura e globalização é uma realidade, e tentar apreendêla neste momento me conduziria a um exercício digressivo. Tomando como horizonte 0 tema que impulsiona este trabalho - 0 cinema realizado em comunidades urbanas de baixa renda -, 0 debate se encaminha para a observação da cultura como recurso (YÚDICE, 2006). Para isso, é necessário considerar dois momentos cruciais para 0 redimensionamento do papel e do lugar na cultura nas últimas décadas: as correntes migratórias impulsionadas pela globalização e 0 fim da Guerra Fria, e com ela 0 término de um intenso patrocínio estatal da arte, uma vez que a produção artística também é uma forma 
de demarcação de espaço e poder. ${ }^{2}$ A partir desses dois processos, nota-se que a globalização impulsionou a transformação de uma série de vetores e artefatos em recurso, e, neste processo, a cultura também passou por tais mudanças, estabelecendo novas relações entre pensamentos que não se reduzem a uma "mera política". Dito de outra forma, a cultura estabelece agora novas relações com a economia e a política, sendo uma importante ferramenta para a melhoria social, para 0 aumento na participação política - uma vez que os partidos políticos, argumenta Yúdice, evidenciam explicitamente sua ineficácia frente aos problemas do cotidiano - e para 0 aprimoramento econômico.

Este argumento percorre diversas partes do planeta e apresenta projetos e iniciativas das mais diferentes naturezas que apostaram na cultura como vetor de transformaçã $0^{3}$. É preciso estar atento apenas para não se tomar a parte pelo todo, pois uma iniciativa com artesanato na cidade de Lima pode não ser tão bem sucedida quanto em Ouro Preto, por exemplo, e os fatores que determinam o sucesso ou o fracasso estão atrelados a uma variável (ou ao cruzamento de variáveis) que pode não passar necessariamente pela cultura, pois, como alertou Canclini (2005, p.45), "todas as práticas sociais contêm uma dimensão cultural, mas nestas práticas nem tudo é cultura". Isto é uma possibilidade. Dessa proposta, interessa reter que o potencial da cultura como recurso torna o debate atual e pertinente, uma vez que projetos culturais, dos mais diferentes tipos e formatos, integram hoje a pauta dos administradores públicos, do mercado e da sociedade civil, que enxergam a cultura como ativos gerentes do social, de modo que este aspecto não pode ser negligenciado. Logo, tal discussão é importante, porque traz a cultura para 0 centro de um debate em que não se pode mais negligenciar seus usos políticos, materiais e concretos, pois é exatamente na esfera do uso, em vez de elaborações conceituais abstratas, que a reflexão se torna relevante.

Situado também nos estudos que investigam os usos da cultura, Teixeira Coelho (2008) se debruça sobre as políticas públicas que apostam na cultura como uma importante peça no cenário da atualidade. Sua perspectiva questiona se a cultura deve, de fato, ser vista como garantidora do bem-estar social. Para isso, duas materializações culturais antagônicas, mas não desconexas, são identificadas: de um lado, a cultura objetiva, aquela que "o hábito e as regras reconhecem como tal" (COELHO, 2008, p.94), ou seja, uma cultura da ordem do oficial,

Yúdice ressalta apenas a questão no lado norte-americano, mas esta observação também serve para o lado soviético, que, antes da Guerra Fria, já utilizava o cinema, por exemplo, como uma ferramenta de difusão de idéias.

Sobre o caso norte-americano, por exemplo, Yúdice aponta que o setor das artes e da cultura pode "melhorar a educação, abrandar a rixa racial, ajudar a reverter a deterioração urbana através do turismo cultural, criar empregos, diminuir a criminalidade, e talvez tirar algum lucro" (2006, p. 29). Este é apenas um exemplo entre tantos descritos, e que vem a reforçar seu argumento inicial sobre o potencial transformador da cultura. 
do grandioso, que se mostra representativa de uma comunidade, mas que, apesar de sua existência evidente, não acessa os sujeitos, não os toca, tornando-se, segundo o autor, um inerte cultural; de outro, existe uma cultura que instiga a capacidade de criação dos indivíduos, que é da ordem do subjetivo, daí a denominação de cultura subjetiva. $^{4}$

Esta perspectiva identifica um descompasso na evolução desses dois estratos culturais, pois, enquanto o primeiro se situa no campo das idéias, o segundo se localiza no âmbito da prática. Se 0 inerte cultural, como entende 0 autor, é uma realidade, exige uma releitura da concepção já intocada de cultura como positividade, pois são diferentes os objetivos e necessidades que cada um desses tipos de cultura empreende. Logo, 0 autor chama a atenção para o reconhecimento da negatividade da cultura ao argumentar que:

Todas as formas constitutivas da sociedade e do imaginário humano, e entre elas sobretudo a cultura e a arte, devem contribuir para a reforma do homem e da sociedade. Eu disse devem e não podem porque isso se trata: da elaboração de uma agenda impositiva que designa funções e papéis para a cultura e a arte sem saber se a natureza ou a constituição de uma e outra se presta ou em que condições e graus se presta ao que delas assim se espera, em especial quando comparadas ao direito e à ciência, por exemplo. (COELHO, 2008, p.91, grifos do autor)
Assim como a proposta da cultura como recurso, esta também direciona seu enfoque para os usos culturais, num momento em que as políticas públicas pautadas na cultura enxergam-na como uma importante composição capaz também de gerenciar o social. Embora os posicionamentos sejam divergentes, eles encaminham a discussão para 0 entendimento da cultura como práxis. Corroborar a negatividade da cultura ou sua capacidade de agente transformador das esferas políticas e econômicas pode ser visto, inicialmente, como algo para não se perder de vista, para ser pensado e debatido, mas que não se apresenta como uma questão crucial para este trabalho. Mais do que se filiar a posicionamentos que se pretendem categóricos, interessa apreender das discussões aquilo que contribui para o desenvolvimento do argumento aqui apresentado.

As ideias apresentadas até então, em suas diferentes abordagens e posicionamentos, constituem-se como um rico painel para se pensar a cultura e seus usos hoje: 0 reconhecimento de sua importância como campo da produção artística (WILLIAMS, 2007) se vincula às propostas posteriores descritas, tais como a de Yúdice (2006) e Coelho (2008), que debatem as funções que a cultura são capazes

Elas não estão em campos isolados, mas travam conexões entre si: A cultura subjetiva é aquilo que a cultura objetivada será mais tarde, modificada: é a parte da cultura objetiva que penetra na subjetividade e com ela se funde e é, igualmente, por outro lado, aquilo que eventualmente jamais será reconhecido como cultura objetivada ou objetiva (2008, p. 94) ou ainda: "a cultura surge do eterno conflito entre a cultura da vida, a cultura subjetiva, produtora de formas culturais ativas postas em prática aqui-e-agora pelos indivíduos criadores (...) e as formas culturais reificadas, relativamente congeladas, que constituem a cultura objetivada". (2008, p. 97) 
ou não de exercer. Da produção artística, que é sempre reflexo de condições históricas e sociais do seu tempo (WILLIAMS, 2007), dos impactos deste tempo na cultura (APPADURAI, 1994), e quais são os seus usos (YÚDICE, 2006; COELHO, 2008), voltamos novamente à reflexão elaborada por Williams. Este cruzamento de posições prepara o terreno para o próximo ponto da discussão deste texto: a simbiose que se estabelece entre cultura, política e cotidiano a partir de um olhar global para a produção de documentários das periferias brasileiras. Para tanto, é necessário debater os outros dois pilares deste tripé.

\section{Arte, cinema e política}

Debater as configurações da cultura acena para a necessidade de se checar que usos são possíveis apreender daí. Para tal, uma delimitação é necessária. Seria inviável discutir quais usos são perceptíveis sem antes tomar como eixo norteador o objeto de estudo em questão. Sendo assim, um olhar mais próximo para esta produção audiovisual indica um acentuado caráter político tanto no discurso dos realizadores quanto nos filmes. Mas não o uso político em seus sentidos consagrados - a cultura a serviço de regimes de direita ou esquerda, ou a cultura como ferramenta de luta contra regimes ditatoriais -, e sim um político provocador de contradições pessoais e coletivas, que instiga a consciência e a imaginação transformadora dos aspectos mais cotidianos, que produz interlocutores, e não apenas espectadores; que frutifica ações eficazes, e não somente gozo ou alienação. Em suma, pensar o uso político da arte como uma práxis que se elabora e reelabora nas experiências diárias. Vejamos de forma mais detalhada como se arquiteta este debate.

Em um texto de 1968, intitulado Arte $y$ compromisso, o documentarista Santiago Álvarez (2003) ressalta a importância da arte como uma ferramenta para se denunciar injustiças e fissuras sociais. Escrito num momento em que América Latina vivia ditaduras militares em diversos de seus países, não é estranho perceber o tom de manifesto e convocatória diante da situação política da época. A defesa do cineasta é de que as artes, e em especial o cinema, devem ser utilizadas como "armas de combate" (ÁLVAREZ, 2003, p. 458, tradução nossa) frente às "misérias do mundo" (BOURDIEU, 2003). Álvarez não enfoca suas atenções apenas neste potencial, mas destaca a necessidade de engajamento por parte do artista, que deve "contribuir para o desenvolvimento cultural do seu povo" (ÁLVAREZ, 2003, p. 458, tradução nossa). E, ao mesmo tempo, ter a clareza do que sua obra representa para a realidade em que se insere. ${ }^{5}$ Vê-se, neste caso, a defesa de um cinema que deve ser realizado em consonância com os 
acontecimentos políticos e sociais da época, ou seja, um cinema que reage frente à instalação de regimes ditatoriais, conectando-se a um dos usos "consagrados" referidos anteriormente.

Um outro uso pode ser discutido a partir de um estudo que toma como corpus um conjunto de filmes realizados principalmente na primeira metade do século XX, em sua grande maioria de propaganda política, para se verificar os vínculos entre cinema e política (FURHAMMAR; ISAKSSON, 1976). Não pretendo aqui descrever exaustivamente ou parafrasear o trabalho, mas sim perceber que o político entra no debate muito mais por uma via temática do que discursiva. É inegável que tal abordagem se situa dentro de uma proposta que verifica as relações entre cinema e política, pois os filmes abordados ${ }^{6}$ foram confeccionados para atender a uma demanda de regimes políticos. Mais do que enxergar um cinema político pela chave da revolução ou do atendimento aos ideais de um tipo de regime, interessa-me tomar como ponto de partida o questionamento ainda atual presente no final da obra:

[...] são as intenções ou os efeitos que fazem de um filme ato político, e até que ponto isso depende de fatores externos como o modo da platéia encará-lo, as análises dos críticos ou julgamento da posteridade. Como, então, descobrir que implicações podem ser autenticamente encontradas num filme?" (FURHAMMAR; ISAKSSON, 1976, p. 222).

Responder a essa indagação, sem dúvida, não é uma tarefa das mais simples. Ela sinaliza para 0 reconhecimento da importância do contexto histórico e da análise fílmica para se avaliar uma determinada produção cinematográfica, pois ambos os aspectos se completam e enriquecem 0 debate pautado nessa perspectiva. Como salientei anteriormente, a necessidade de se discutir 0 cinema de periferia observando as relações entre cultura, política e cotidiano favorece 0 surgimento de uma seara múltipla cuja reflexão está envolta pelos mitos, ambigüidades e dissonâncias presentes na vida dos homens. Uma resposta ao questionamento proposto por Furhammar e Isaksson (1976), que aqui se configura muito mais como uma provocação do que como 0 epicentro do debate, deve reconhecer as interfaces entre política e outros campos. Aliás, é numa perspectiva horizontal que a reflexão se torna, de fato, possível, pois a política não é um objeto localizado num pedestal isolado. A multiplicidade de "triângulos" analíticos é possível, assim como as combinações dos "ângulos". A relação que a política trava com outros "campos" oxigena 0 diálogo em seus diversos pontos de conexão com a realidade em que emerge. Ao situar o debate no âmbito do documentário, pode-se percebê-lo como um espaço privilegiado, por exemplo, para as articulações entre política, ética e ideologia (NICHOLS, 1991). Esses três aspectos operam uma organização social, bem como o tecido e a textura de uma determinada economia cultural, 
de modo que uma política da ética e uma ética da política podem se materializar em discursos ideológicos. ${ }^{7}$ Este posicionamento evidencia que ética, política e ideologia podem ser cambiantes, capazes de dividir a mesma arena. Esta pequena digressão ressalta a necessidade de se debater a relação entre arte e política, bem como o que se denomina arte política.

Apontei anteriormente duas possibilidades de materializações para a relação entre arte, cinema e política - atender às necessidades de regimes totalitários, atender às necessidades da revolução. Não quero aqui desmerecê-las ou sugerir que sua importância reside apenas no passado, afinal ainda vivemos sob a égide de regimes totalitários e diversos grupos ainda lutam contra tais regimes, mesmo que em menor proporção em relação aos últimos 40 anos. Porém, diante do cenário contemporâneo atual, para avançar no debate, é preciso visualizar outras materializações para essa relação. A coexistência e interferência entre si de diversos "panoramas", para retomar o termo proposto por Appadurai (1994), reforça também a necessidade de um olhar mais detalhado para a relação que se estabelece entre arte, cinema e política.

A arte revela 0 seu potencial político a partir do momento em que investe e problematiza a esfera das relações para criar apresentações, e não necessariamente representações. Quando balizada no relacional, ela é capaz de elaborar experiências que são levadas adiante, em diferentes graus, níveis e contextos, produzindo resultados artísticos concretos de uma realidade existente, apresentando-se como um "interstício social" (BOURRIAUD, 2009, p.19), em que suas variáveis culturais, políticas e estéticas gravitam em torno de um objetivo comum: compartilhar 0 espaço público a partir de estratégias, interesses e sentimentos comuns, bem como, numa chave oposta, abalar as estruturas de tal proximidade comumente vivenciadas, produzindo erosões e crises. ${ }^{8} \mathrm{~A}$ arte evidencia seu caráter político quando reforça as relações humanistas, e não simplesmente as humanitárias. Quando instiga o debate ao tornar a palavra um ato revolucionário atento agora às artimanhas das redes e da globalização, algo feito muito mais pelo documentário fotográfico ou cinematográfico, como testemunha, do que pelo jornalismo, que se tornou uma espécie de "cão de guarda dos acontecimentos" (BAQUÉ, 2004, p. 177, tradução nossa). Atenta ao fato de que o mundo não é mais clivado por dualismos do tipo opressor/ oprimido, patrão/empregado, a arte política

Nichlols (1991, p. 103, tradução nossa) ressalta: "em vez de conceber a ética como um meio através do qual podemos avaliar e hierarquizar as práticas do cinema documentário, um enfoque alternativo seria desfamiliarizar esta prática e colocá-la dentro de outra. A tentativa de que questionar e subverter a ideologia dominante de oposições e hierarquia e a ética que a respalda. Para além do bem e do mal é a dialética de uma prática social baseada em diferenças que não se reduzem a eles e outros, eu e outro."

Frodon (2007, p. 436) esclarece a relação: “Lembro que nenhum desses dois 'campos' considera o estado do mundo e das relações humanas como algo adquirido indiscutivelmente nem como algo óbvio: ambas as abordagens pressupõem uma insatisfação com a realidade". 
apresenta a possibilidade de pensamento e ação, e, diante das agruras do mundo, convoca 0 artista, o cineasta ou o documentarista a reagir, de alguma forma, frente a essas adversidades, pois estimular a reflexão reativa 0 político. Se ontem havia a arte política pautada nas lutas contra os regimes ditatoriais, hoje há uma arte que não aceita passivamente os desígnios da globalização, e se articula em torno de movimentos anti-globalização, pois os momentos de crise forçam a criatividade e a necessidade de se aproximar do público, de travar uma interlocução que não toma como baliza somente uma historização política da arte, uma filosofia política dogmática ou uma restrição às obras de artistas engajados, mas, acima de tudo, um cruzamento dessas possibilidades. A arte se torna política quando reflete sobre sua importância, impacto e alcance diante das perdas de sentido e do colapso da política. Enfim, a envergadura política da arte se revela quando ela não apresenta intenções políticas explícitas para ser política. No esteio dessa discussão entre política e sua relações com as formas artísticas, recorro aqui ao pensamento de Baqué (2004), Bourriaud (2009) e Frodon (2007). Cada um deles, voltado para aquilo que lhe é mais caro - arte contemporânea e documentário, especialmente -, ressalta a importância de se pensar os afluentes políticos da arte, sinalizando para a necessidade de tomar a política em consonância com a arte como uma práxis. As capacidades destacadas anteriormente, sem dúvida, sinalizam para um papel transformador e, ao mesmo tempo, desafiador para arte em tempos atuais. Mas uma vez ressaltada a importância do uso da cultura e da arte - e vimos até que ela revela um intenso potencial político -, resta saber que efeitos tais manifestações artísticas são capazes de empreender. Não quero com isso afirmar que a arte política só faça sentido e só mereça atenção a partir do momento em que se constatam claramente suas eficazes conseqüências, até porque as intenções são diversas e as opiniões sobre seu impacto podem variar com o referencial adotado. Dependendo do tipo de arte que se ponha em prática, um resultado plausível pode demorar para vir à tona, não somente para 0 realizador, como também para o público. A questão é que os aspectos que pontuam a relação entre arte e política solicitam mudanças - seja em relação às ações ou às formas de pensamento. Diante disso, torna-se válido, então, checar esse desdobramento da arte política. Pensar a arte política requer também pensar o seu raio de alcance e, quiçá, possíveis mudanças por ela proporcionadas.

Reconhecer que, apesar de bem intencionada, a arte não pode tudo é um primeiro passo para a discussão sobre sua práxis. Sem perder de vista que ela emerge em contextos históricos pontuais e reflete as variáveis de sua época, seria ingênuo, então, pensar que por si só ela seja capaz de mudar o mundo. 0 cenário descrito por Baqué (2004) apresenta uma crise da informação e da imagem, que delega cada vez menos espaço 
para 0 intelectual e gerencia uma espécie de pânico generalizado diante das imagens. Mas situando suas análises das obras de artes e filmes, na compreensão do contexto em que elas se estabelecem, a autora destaca a mutabilidade estética que os momentos de crise proporcionam, e chama a atenção para a "impossibilidade de se falar de arte política, sem mirar o olhar para as fraturas sociais, para os imaginários sobre a guerra e para a recondução da problemática do verdadeiro e do falso, presente na Grécia Antiga que hoje encontra singulares ecos" (BAQUÉ, 2004, p. 196, tradução nossa) $)^{9}$. Seguindo as trilhas de Baqué, concentrarei as atenções no documentário, por ser 0 objeto de estudo deste trabalho, e também para não abrir demais a discussão e querer passar por todo tipo de projeto artístico. Pois o documentário há bastante tempo traz para si a tarefa de debater questões espinhosas mundo afora. 0 documentário é político mesmo quando não tem a intenção de ser (BAQUÉ, 2004, p. 260).

Pensar o documentário dentro dessa conjuntura passa inevitavelmente por enxergá-lo como uma materialização de um engajamento político, aspecto que emergiu com força nos anos 60 e que até os dias de hoje impulsiona a confecção do "documentário engajado", ou seja, um documentário cuja fidelidade política aparece em primeiro plano para lidar com os problemas sociais. A discussão em torno do documentário como uma ferramenta de mudança remete novamente 0 debate para a pergunta apresentada anteriormente: é possível mensurar as conseqüências e 0 alcance de um filme? No artigo Political Mimesis, Jane M. Ganes (1999) reflete sobre a questão ao salientar um aspecto ao mesmo tempo antagônico e complementar: os documentários não têm o poder de modificar situações políticas, a mudança social empreendida pelo documentário é uma utopia sustentada pela esquerda. Tal instância, segundo a autora, não deixa de interferir inclusive na forma como se encaram as mudanças: "em paralelo ao desenvolvimento da produção de documentários, na teoria política ocidental, 'mudanças sociais' são vistas como 'revolução', desconectada de uma forma que nos conduz a vê-la como algo não realizável, oposto às possibilidades cotidianas" (GANES, 1999, p.87, tradução nossa). Mas, por outro lado, Ganes chama a atenção, como faz também Baqué (2004), para a necessidade do novo vídeo de guerrilha urbana priorizar em suas discussões uma estética política do documentário, e este movimento não pode ser negligenciado pela crítica e pela academia, pois os documentários usam cópias de imagens do mundo para influenciar o mundo (GANES, 1999, p.100). Se documentários são cópias do mundo em imagens, é necessário reconhecer que -

A autora ainda segue: "Nem a arte pela arte, nem somente a auto-reflexividade modernista, mas sim uma vocação da arte: eminentemente frágil, jamais assegurada em sua recepção, nem, menos ainda de sua eficácia, ela se condena de uma certa maneira à 'consciência infeliz' hegeliana”. (Baqué, 2004, 196-197, tradução nossa). 
diante da pluralidade de rotas para a arte e 0 documentário, mas cujo ponto de chegada único é a necessidade de empreender discussões para reativar o político - pensar esta possibilidade a partir do cotidiano, então, torna-se uma estratégia política particularmente importante, pois a imaginação e a reflexão transformadoras que os artefatos artísticos podem proporcionar atingem desde 0 "mundo", como dito anteriormente, até as esferas da vida cotidiana.

\section{0 cotidiano como estratégia política}

No entanto, destacar a importância do cotidiano como uma estratégia para produzir imagens políticas não implica recorrer aos pormenores, às pequenas coisas da vida, ao sem importância, e ressaltar, a partir daí, uma beleza, leveza ou delicadeza que somente a experiência cotidiana é capaz de revelar. Se o cotidiano, pois, estabelece as articulações entre a política e a história (MARTINS, 2008), é imprescindível reconhecer que ele também pode ser opressor e produtor de agruras, que cotidiano não se restringe ao ambiente privado, interno e particular. Tampouco se pode enxergá-lo como lugar privilegiado do marasmo, do banal, da repetição, pois o cotidiano não escapa às ações humanas. Aliás, são elas que engendram 0 cotidiano, sendo ele desta forma constantemente atravessado por conflitos, guerras, violência, desigualdades, desastres, acidentes, separações, enfim, a lista pode ir ao infinito. Ressalto aqui este aspecto, para que não se veja o cotidiano como um refúgio do "mundo terrível lá fora", e para que se evitem visões restritas e idealizações. Mas também não quero com isto me situar na chave oposta do debate, ou seja, enxergar o cotidiano apenas a partir das adversidades da vida, mas sim atentar para as múltiplas facetas que ele pode apresentar.

A ressalva anterior, de certa forma, já anuncia 0 terreno no qual me situo acerca da forma como o cotidiano pode ser encarado. Nos ciências sociais, o cotidiano vem sendo tratado de forma mais estreita, relevando uma abundância de referências, perspectivas e correntes.

Diante desse aspecto, para que se evite um detalhamento exaustivo sobre esta diversidade, recorro a trabalhos (PAIS, 2003; MARTINS, 2008) cujo enfoque se encaminha para a apreensão do cotidiano em suas materialidades (não no sentido marxista literal e restrito) no contexto social, político e histórico, distanciando-se de perspectivas abstratas e subjetivas, muitas vezes pautadas em impressões meramente pessoais. ${ }^{10}$ Sendo assim, deve-se destacar inicialmente 0 cotidiano como o local da produção e circulação de conhecimentos e significados comuns, que, pautado em "situações de interação" (PAIS, 2003, 
p. 15), permite 0 "surgimento de contradições"

(MARTINS, 2008, p. 56), exigindo dos indivíduos saber lidar com tensões e instabilidades em constantes processos de negociação e mediação. Este conhecimento comum, por vezes visto como algo não merecedor de atenção nas ciências sociais ${ }^{11}$, é a fonte primária para as experiências que possibilitam os modos de ser, estar e fazer na vida cotidiana, e por ser sempre um processo em que 0 "vivido" (PAIS, 2003, p. 47; MARTINS, 2008, p.95), como um momento de compartilhamento de sentidos e informações, torna-se imprescindível para a compreensão mais apurada do cotidiano. Com base nessa orientação, a materialização referida anteriormente se torna mais nítida, palpável, pois, como salienta Pais, não se pode tomar 0 cotidiano como uma categoria distanciada das experiências sociais. 0 desafio que se coloca ao pesquisador diante deste tema "é o de conseguir abrir brechas num debate social polimorfo" (PAIS, 2003, p. 75), já que um dos pilares que sustentam os estudos com foco no cotidiano é exatamente a dificuldade em apreender "o imprevisível, o aleatório, o imprevisto" (PAIS, 2003, p. 81) presente nas experiências cotidianas. $^{12}$
Aderindo à proposta de Pais, ou seja, do cotidiano como "revelador dos processos sociais de transformação da sociedade e de seus conflitos" (PAIS, 2003, p. 72), pode-se seguir no debate ressaltando um aspecto mais específico do quadro geral apresentado até então. Se o cotidiano, como insiste 0 autor, é fonte de interação, contradiçãa, produção e troca de conhecimento, torna-se importante lançar o olhar para as materialidades desta composição, para, a partir daí, poder afirmar que no cotidiano 0 homem descobre a eficácia das ações políticas (MARTINS, 2008, p. 52), pondo-se em prática as condições de transformação da política e da história. Este aspecto reforça a necessidade de se olhar para o cotidiano a partir da chave que preza pelo "histórico-original-significativo", em vez de "quotidiano-banal-insignificante", para utilizar os termos de Pais (2003, p. 74). No contexto da produção audiovisual debatida neste trabalho, para continuar a discussão é necessário atentar para a primeira tríade apontada por Pais. Não interessa, aqui, verificar seus componentes em separado, mas observar que efeitos as intersecções entre eles são capazes de produzir. Para tanto, a idéia de que 0 tempo histórico se manifesta na vida cotidiana (MARTINS, 2008) sinaliza para a percepção do 
cotidiano como uma negociação de inserção social, política e histórica, tornando-se a base para a implementação de ações, sistemas de pensamento e construções de significados. Se, por um lado, Martins, apoiado em Lefebvre, sustenta que "divorciado do processo histórico que o produz o cotidiano não faz sentido"(MARTINS, 2008, p. 52); por outro, mas de forma complementar, Pais sublinha que não se deve enxergar a vida cotidiana distanciada do social, pois este pressuposto leva em conta que o tempo e o espaço, como alicerces da história, são preenchidos por experiências concretas que atravessam as esferas do político, do social, do cultural. Logo, o tempo histórico das ações cotidianas, como destaca Martins, só pode ser pensado quando se posiciona uma lupa sobre tais modulações.

Debater os pilares de sustentação desse tipo de cinema é uma maneira de reconhecer seus potenciais enunciativos, talvez pelo fato de não se situarem fixamente num campo, mas também pela força desestabilizadora que 0 encontro de tantas possibilidades pode gerar. Este cruzamento de possibilidades pode soar desafiador, por ser um terreno inesgotável, em que sua apreensão tácita reside apenas no desejo de se apreender algo que não se apreende por completo, porque, em sua essência, já está fadado às infindáveis possibilidades comunicativas da vida cotidiana.

\section{Referências}

ÁLVAREZ, Santiago. "Arte y compromisso". In: PARANAGUÁ, Paulo Antonio (org.). Cine documental en América Latina. Madrid: Cátedra, 2003, p. 458-460. APPADURAI, Arjun. Disjunção e diferença na economia cultural global. In: FEATHERSTONE, Mike (org.). Cultura global: nacionalismo, globalização e modernidade. Petrópolis: Vozes, 1994. p. 311-327. Dimensões culturais da globalização. Lisboa: Teorema, 2005.

BAQUÉ, Dominique. Pour um nouvel art politique: de l'art contemporain au documentaire. Paris: Flammarion, 2004.

BOURDIEU, Pierre (org.). A miséria do mundo. 5. ed. Petrópolis: Vozes, 2003.

BOURRIAUD, Nicolas. Estética relacional. São Paulo: Martins Fontes, 2009.

CERTEAU, Michel de. A invenção do cotidiano. Vol. 1. 14. ed. Petrópolis: Vozes, 2008.

COELHO, Teixeira. A cultura e seu contrário. São Paulo: Iluminuras; Itaú Cultural, 2008.

FROD0N, Jean-Michel. "Os desafios políticos do cinema". In: NOVAES, Adauto (org.). 0 esquecimento da política. Rio de Janeiro: Agir, 2007, p.433-442.

FURHAMMAR, Leif; ISAKSSON, Folke. Cinema \&

Política. São Paulo: Paz e Terra, 1976.

GAINES, Jane M.. "Political mimesis". In: GAINES, Jane M. \& RENOV, Michael (orgs.). Collecting Visible Evidence. Minnesota: University of Minnesota, 1999, p.84-102.

GARCÍA CANCLINI, Nestor. Diferentes, desiguais e desconectados: mapas da interculturalidade. Rio de Janeiro: Editora UFRJ, 2005.

GOFFMAN, Erving. A representação do eu na vida cotidiana. 15. ed. Petrópolis: Vozes, 2008. 
HELLER, Agnes. 0 cotidiano e a História. 8. ed. São Paulo: Paz e Terra, 2008.

LEFEBVRE, Henri. A vida cotidiana no mundo moderno. São Paulo: Ática, 1991.

MARTINS, José de Souza. A sociabilidade do homem simples. São Paulo: Contexto, 2008.

NICHOLS, Bill. Representing reality. Bloomington: Indiana University Press, 1991.

PAIS, José Machado.Vida cotidiana: enigmas e revelações. São Paulo: Cortez, 2003.

WILLIAMS, Raymond. Palavras-chave: um vocabulário de cultura e sociedade. São Paulo: Boitempo, 2007.

YÚDICE, George. A conveniência da cultura: usos da cultura na era global. Belo Horizonte: UFMG, 2004. 


\begin{tabular}{|l|l|l|}
\hline $\begin{array}{l}\text { Culture, politics and } \\
\text { everyday life: pillars of support } \\
\text { for a peripheral cinema }\end{array}$ & $\begin{array}{l}\text { Cultura, política y } \\
\text { cotidiano: pilares de apoyo } \\
\text { a un cine periférico }\end{array}$ \\
\hline $\begin{array}{l}\text { Abstract } \\
\text { From the cinema made in Brazilian urban periphery, } \\
\text { this paper discusses the composition and functions } \\
\text { of three major pillars that support it: culture, politics } \\
\text { and everyday life. The perspective adopted here is } \\
\text { that culture, politics and everyday life are related in } \\
\text { a contiguous way, and are articulated in the debate } \\
\text { about the potential of cultural products also among } \\
\text { the new configuration of politics, using the everyday } \\
\text { as a strategy to review orders of images, discourses } \\
\text { and points of view. }\end{array}$ & $\begin{array}{l}\text { Resumen partir del cine realizado en periferias urbanas } \\
\text { Keywords } \\
\text { Culture. Politics. Everyday life. Peripheric cinema. }\end{array}$ & $\begin{array}{l}\text { y las funciones de tres importantes pilares que } \\
\text { lo sostienen: cultura, política y cotidiano. La } \\
\text { perspectiva aqui adoptada es que cultura, política } \\
\text { y cotidiano se cruzan de manera contigua, y se } \\
\text { articulan para promover el debate acerca del } \\
\text { potencial de los productos culturales en medio, } \\
\text { también, a las nuevas configuraciones de la esfera } \\
\text { política, que recurre a lo cotidiano como una } \\
\text { estrategia para rever ordenamientos de imagenes, } \\
\text { enunciados y puntos de vista. }\end{array}$ \\
\hline
\end{tabular}




\section{Expediente}

A revista E-Compós é a publicação científica em formato eletrônico da Associação Nacional dos Programas de Pós-Graduação em Comunicação (Compós). Lançada em 2004, tem como principal finalidade difundir a produção acadêmica de pesquisadores da área de Comunicação, inseridos em instituições do Brasil e do exterior.
E-COMPÓS I www.e-compos.org.br I E-ISSN 1808-2599

Revista da Associação Nacional dos Programas de Pós-Graduação em Comunicação. Brasília, v.12, n.2, maio/ago. 2009

A identificação das edições, a partir de 2008 passa a ser volume anual com três números.

\section{CONSELHO EDITORIAL}

\section{Afonso Albuquerque}

Universidade Federal Fluminense, Brasil

Alberto Carlos Augusto Klein

Universidade Estadual de Londrina, Brasi

Alex Fernando Teixeira Primo

Universidade Federal do Rio Grande do Sul, Brasi

\section{Alfredo Vizeu}

Universidade Federal de Pernambuco, Brasil

Ana Carolina Damboriarena Escosteguy

Pontifícia Universidade Católica do Rio Grande do Sul, Bras

Ana Silvia Lopes Davi Médola

Universidade Estadual Paulista, Brasil

André Luiz Martins Lemos

Universidade Federal da Bahia, Brasil

Ângela Freire Prysthon

Universidade Federal de Pernambuco, Brasil

Antônio Fausto Neto

Universidade do Vale do Rio dos Sinos, Brasil

Antonio Carlos Hohlfeldt

Pontifícia Universidade Católica do Rio Grande do Sul, Brasil

Arlindo Ribeiro Machado

Universidade de São Paulo, Brasil

César Geraldo Guimarães

Universidade Federal de Minas Gerais, Brasil

Cristiane Freitas Gutfreind

Pontifícia Universidade Católica do Rio Grande do Sul, Brasil

Denilson Lopes

Universidade Federal do Rio de Janeiro, Brasil

Eduardo Peñuela Cañizal

Universidade Paulista, Brasi

Erick Felinto de Oliveira

Universidade do Estado do Rio de Janeiro, Brasil

Francisco Menezes Martins

Universidade Tuiuti do Paraná, Brasil

Gelson Santana

Universidade Anhembi/Morumbi, Brasi

Hector Ospina

Universidad de Manizales, Colômbia

leda Tucherman

Universidade Federal do Rio de Janeiro, Brasil

Itania Maria Mota Gomes

Universidade Federal da Bahia, Brasil

Janice Caiafa

Universidade Federal do Rio de Janeiro, Brasil

Jeder Silveira Janotti Junior

Universidade Federal da Bahia, Brasil

\section{João Freire Filho}

Universidade Federal do Rio de Janeiro, Brasil

John DH Downing

University of Texas at Austin, Estados Unidos

José Luiz Aidar Prado

Pontifícia Universidade Católica de São Paulo, Brasil

José Luiz Warren Jardim Gomes Braga

Universidade do Vale do Rio dos Sinos, Brasil

Juremir Machado da Silva

Pontifícia Universidade Católica do Rio Grande do Sul, Brasil

Lorraine Leu

University of Bristol, Grã-Bretanha

Luiz Claudio Martino

Universidade de Brasília, Brasil

Maria Immacolata Vassallo de Lopes

Universidade de São Paulo, Brasil

Maria Lucia Santaella

Pontifícia Universidade Católica de São Paulo, Brasil

Mauro Pereira Porto

Tulane University, Estados Unidos

Muniz Sodre de Araujo Cabral

Universidade Federal do Rio de Janeiro, Brasil

Nilda Aparecida Jacks

Universidade Federal do Rio Grande do Sul, Brasil

Paulo Roberto Gibaldi Vaz

Universidade Federal do Rio de Janeiro, Brasil

Renato Cordeiro Gomes

Pontifícia Universidade Católica do Rio de Janeiro, Brasil

Ronaldo George Hela

Universidade do Estado do Rio de Janeiro, Brasil

Rosana de Lima Soares

Universidade de São Paulo, Brasil

Rossana Reguillo

Instituto Tecnológico y de Estudios Superiores do Occidente, México

Rousiley Celi Moreira Maia

Universidade Federal de Minas Gerais, Brasil

Sebastião Carlos de Morais Squirra

Universidade Metodista de São Paulo, Brasil

Simone Maria Andrade Pereira de Sá

Universidade Federal Fluminense, Brasi

Suzete Venturelli

Universidade de Brasília, Brasil

Valério Cruz Brittos

Universidade do Vale do Rio dos Sinos, Brasil

Veneza Mayora Ronsini

Universidade Federal de Santa Maria, Brasil

Vera Regina Veiga França

Universidade Federal de Minas Gerais, Brasil
COMISSÃO EDITORIAL

Ana Gruszynski I Universidade Federal do Rio Grande do Sul, Brasil Felipe da Costa Trotta I Universidade Federal de Pernambuco, Brasil Rose Melo Rocha I Escola Superior de Propaganda e Marketing, Brasil

\section{CONSULTORES AD HOC}

Aníbal Francisco Alves Bragança I Universidade Federal Fluminense, Brasil Benjamim Picado I Universidade Federal da Bahia, Brasil

Carlos Eduardo Franciscato I Universidade Federal de Sergipe, Brasi

Christa Liselote Berger I Universidade Vale do Rio dos Sinos, Brasil

Gisela Castro I Escola Superior de Propaganda e Marketing, Brasil

Luciana Pellin Mielniczuk I Universidade Federal de Santa Maria, Brasi

Marcia Benetti I Universidade Federal do Rio Grande do Sul, Brasil

Paulo Cunha Carneiro Filho I Universidade Federal de Pernambuco, Brasil

Raquel Recuero I Universidade Católica de Pelotas, Brasil

REVISÃO DE TEXTO E TRADUÇÃO I Everton Cardoso

EDITORAÇÃO ELETRÔNICA I Raquel Castedo
COMPÓS I www.compos.org.br

Associação Nacional dos Programas de Pós-Graduação em Comunicação

Presidente

Itania Maria Mota Gomes

Universidade Federal da Bahia, Brasil

itania@ufba.br

Vice-presidente

Julio Pinto

Pontifícia Universidade Católica de Minas Gerais, Brasil

juliopinto@pucminas.br

Secretária-Geral

Ana Carolina Escosteguy

Pontifícia Universidade Católica do Rio Grande do Sul, Brasil

carolad@pucrs.br 